\title{
Space Nuclear Power: Opening the Final Frontier
}

\author{
Gary L. Bennett* \\ Metaspace Enterprises, Emmett, Idaho, U.S.A.
}

\begin{abstract}
$\underline{\text { Abstract }}$
Nuclear power sources have enabled or enhanced some of the most challenging and exciting space missions yet conducted, including missions such as the Pioneer flights to Jupiter, Saturn, and beyond; the Voyager flights to Jupiter, Saturn, Uranus, Neptune, and beyond; the Apollo lunar surface experiments; the Viking Lander studies of Mars; the Ulysses mission to study the polar regions of the Sun; the Galileo mission that orbited Jupiter; the Cassini mission orbiting Saturn and the recently launched New Horizons mission to Pluto. In addition, radioisotope heater units have enhanced or enabled the Mars exploration rover missions (Sojourner, Spirit and Opportunity). Since 1961, the United States has successfully flown 41 radioisotope thermoelectric generators (RTGs) and one reactor to provide power for $\mathbf{2 4}$ space systems. The former Soviet Union has reportedly flown at least 35 nuclear reactors and at least two RTGs to power 37 space systems.
\end{abstract}

\section{Introduction}

The development and use of nuclear power in space has enabled the human race to extend its vision into regions that would not have been possible with non-nuclear power sources. For example, in the bitterly cold, radiation-rich, poorly lit environments of the outer planets, only a rugged, solar-independent power source has the wherewithal to survive and function for long periods of time. Even closer to the Sun, environments can be too harsh or otherwise inhospitable for more conventional power sources. For example, the long lunar nights ( 14 Earth days) create a major penalty for solar-powered systems. The frigid, dimly lit polar regions of Mars are another potentially difficult location in which to operate non-nuclear power sources for long periods of time.

Serious studies (such as Project Feedback) of using the immense potential energy of the nucleus for power and propulsion in space began in the U.S. shortly after the end of World War II. At a time when the full potential of more conventional power and propulsion systems was not yet fully realized, nuclear systems promised advantages in opening up the final frontier of space. These early studies identified two types of nuclear power sources of potential interest: radioisotope power sources and nuclear reactors. ${ }^{1}$

With advances in the more conventional technologies such as solar cells and batteries it was more advantageous to use those technologies for the first space flights, particularly since those early missions were in Earth orbit and of short duration.

However, NASA and its predecessor the National Advisory Committee on Aeronautics (NACA) realized early on the need for nuclear systems in space if the Solar System was to be explored. During the Cold War, the U.S. Department of Defense also realized the inherent advantages of nuclear systems, particularly their hardness against certain types of countermeasures.

Following on these early mission studies, the U.S. Atomic Energy Commission (USAEC), beginning in 1951, requested several studies on using radioisotopes and nuclear reactors to power spacecraft. As these studies were being completed, K. C. Jordan and J. H. Birden, two researchers working at what was then the USAEC's Mound Laboratory (then operated by Monsanto Research Corporation), built the first radioisotope thermoelectric generator (RTG) in 1954. Even though this first RTG produced only $1.8 \mathrm{mWe}$ of power it demonstrated the feasibility of coupling radioisotopes with thermocouple-type (thermoelectric) conversion systems. ${ }^{1}$

*5000 Butte Road; Emmett, Idaho 83617-9500; Fellow 
Table 1 summarizes the U.S. space missions that have utilized or are utilizing nuclear power. The following sections discuss the various missions in the order shown in Table 1. The interested reader is referred to References 2, 3, and 4 for more details. Table 1 does not include those missions that used only radioisotope heater units (RHUs).

All of the U.S. space nuclear power systems used thermoelectric technology to convert the heat (thermal power) from the radioisotope heat source or nuclear reactor into electrical power. The U.S. did, however, support research into more advanced conversion technologies, including dynamic conversion (Brayton, Rankine, Stirling). The early RTGs used telluride-based materials in their thermoelectric elements. The SNAP-10A space nuclear reactor power system and the RTGs on all missions beginning with Lincoln Experimental Satellites (LES) 8 and 9 (1976) used silicon-germanium alloys. Unless otherwise indicated, mission information in this paper was taken from Web sites maintained by the mission organizations or the National Space Science Data Center $<\mathrm{http}: / /$ nssdc.gsfc.nasa.gov/>.

Table 1. Uses of Space Nuclear Power By The United States

(Spacecraft/Year Launched/Type of Nuclear Power Source*/Beginning-of-Mission Power)

Note: SNAP is an acronym for Systems for Nuclear Auxiliary Power

MHW-RTG = Multi-Hundred Watt Radioisotope Thermoelectric Generator

GPHS-RTG = General-Purpose Heat Source Radioisotope Thermoelectric Generator

\section{Transit Navy Navigational Satellites}

- $\quad$ Transits 4A and 4B (1961) SNAP-3B (2.7 We)

- Transits 5BN-1 and 5BN-2 (1963) SNAP-9A (>25 We)

- $\quad$ Transit TRIAD (1972) Transit-RTG (35 We)

\section{SNAPSHOT Space Reactor Experiment}

- $\quad$ SNAP-10A nuclear reactor (1965) ( $\geq 500 \mathrm{We})$

Nimbus-3 Meteorological Satellite

- $\quad$ SNAP-19B RTGs (1969)(2@28 We each)

\section{Apollo Lunar Surface Experiments Packages}

- Apollos 12 (1969), 14 (1971), 15 (1971), 16 (1972), 17 (1972) SNAP-27 (>70 We each)

\section{Lincoln Experimental Satellites (Communications)}

- $\quad$ LES 8 and LES 9 (1976) MHW-RTG (2/spacecraft @ 154 We each)

\section{$\underline{\text { Interplanetary Missions }}$}

- $\quad$ Pioneer 10 (1972) and Pioneer 11 (1973) SNAP-19 (4/spacecraft @ 40 We each)

- Viking Mars Landers 1 and 2 (1975) SNAP-19 (2/Lander @, 42 We each)

- Voyager 1 and Voyager 2 (1977) MHW-RTG (3/spacecraft@ 158 We each)

- Galileo (1989) GPHS-RTG (2@ 288 We each) (>3-year delay)

- $\quad$ Ulysses (1990) GPHS-RTG (289 We) (>4-year delay)

- Cassini (1997) GPHS-RTG (3@ 295 We each)

- New Horizons (2006) GPHS-RTG (1@245.7 We) (most of fuel >21 years old)

*The odd-numbered SNAP power sources used radioisotope heating while the even-numbered SNAP power sources used nuclear reactors to produce the heat. 


\section{Transit Navy Navigational Satellites}

In 1958, researchers at the Johns Hopkins University Applied Physics Laboratory (JHU/APL) conceived the idea of a navigational satellite based on Doppler technology as part of the APL-proposed Navy Navigation Satellite System. The navigation satellite technologies developed under the Transit program are now in use in the Global Positioning System (GPS). While solar cells and batteries powered these early "Transit" satellites, JHU/APL accepted an offer from the USAEC to have an auxiliary radioisotope power source, denoted by the acronym SNAP3B, for its Transit 4A and Transit 4B satellites. ${ }^{5}$ And with that act the era of space nuclear power was literally launched. The following sections discuss the Transit satellites in the order of launching.

\subsection{Transits 4A and 4B}

Transit 4A was launched on 29 June 1961 and was quickly followed by the launch of Transit 4B on 15 November 1961. The objectives of both missions were (1) to conduct navigation trials and demonstrations; (2) to improve the understanding of the effects of ionospheric refraction on radio waves; and (3) to increase knowledge of Earth's shape and gravitational field. Both spacecraft met all launch objectives. ${ }^{6}$

Each 2.1-kg SNAP-3B RTG (one per spacecraft) produced about $2.7 \mathrm{We}$ at beginning-of-mission (BOM) from a radioisotope heat source that provided a thermal power of about $52.5 \mathrm{Wt}$. While these power levels seem low, both RTGs served to fill a critical niche by powering the crystal oscillator that was the heart of the electronic system used for Doppler-shift tracking. In addition, the RTGs powered the buffer-divider-multiplier, phase modulators, and 54- and 324-MHz power amplifiers. While various component failures interfered with a full analysis of the RTG performance, there were sufficient data from other measurements to show that both RTGs operated well beyond their design life of five years. ${ }^{6.7}$

Figure 1 is an artist's illustration of Transit 4A in space and Figure 2 is a cutaway of the SNAP-3B RTG.

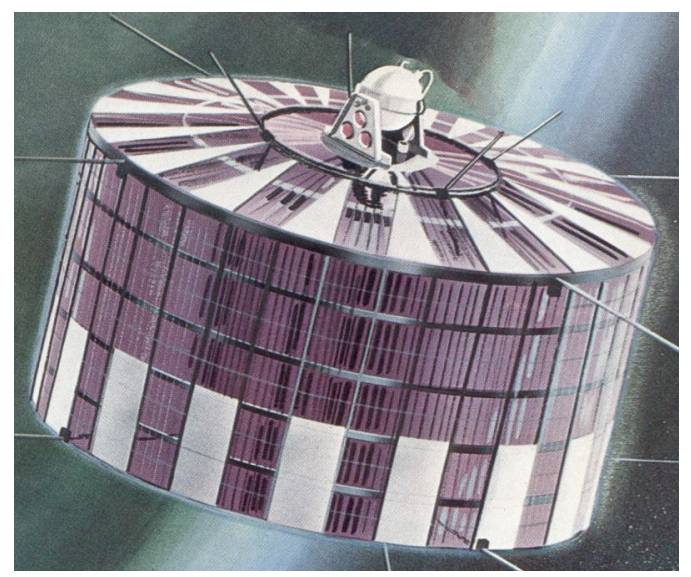

Figure 1. Artist's concept of the Transit-4A satellite in orbit. The SNAP-3B RTG is shown on "top" of the satellite. (Martin Nuclear)

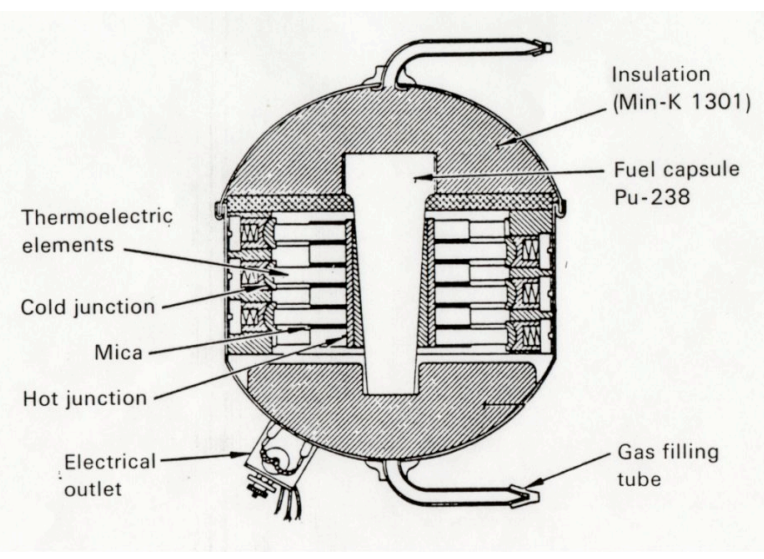

Figure 2. Cutaway of the SNAP-3B RTG. SNAP-3B was $12.1 \mathrm{~cm}$ in diameter and 14-cm high. The power was $2.7 \mathrm{We}$ and the mass was $2.1 \mathrm{~kg}$. (Martin Nuclear)

\subsection{Transits 5BN-1 and 5BN-2}

Based on the successful performance of the SNAP-3B RTGs on the Transit 4A and Transit 4B satellites, JHU/APL had the confidence to design and fly two totally nuclear-powered navigational satellites (Transit 5BN-1 and Transit 5BN-2). Each satellite used a new, higher power RTG designated SNAP-9A. Each 12.3-kg SNAP-9A was designed to provide $25 \mathrm{We}$ at a nominal $6 \mathrm{~V}$ for five years in space after one year of storage on Earth. ${ }^{6,8}$ 
Transit 5BN-1 was launched on 28 September 1963 from Vandenberg Air Force Base (VAFB) in California. Transit 5BN-2 followed a little over two months later on 6 December $1963 .^{6}$

One of the objectives of the Transit $5 \mathrm{BN}$ series was to provide "a means by which U.S. Navy ships may navigate anywhere in the world". ${ }^{6}$ Because of some electronic problems, Transit 5BN-1 partially achieved this objective; nevertheless, JHU/APL reported that "All APL satellite navigational concepts were validated using Satellite 5BN-1".

In a summary report, JHU/APL stated that "Satellite $5 \mathrm{BN}-1$ was the first artificial earth satellite to employ nuclear energy as its primary power source. ... In her role as a pioneer nuclear satellite, 5BN-1 demonstrated the extreme simplicity with which thermoelectric generators may be integrated into the design, not only to provide the electrical power but also to aid in thermal control.",

Transit 5BN-2 reportedly met all launch objectives and was described by JHU/APL as "the first truly operational navigation satellite" ${ }^{6}$

Figure 3 is an artist's conception of the Transit $5 \mathrm{BN}-1$ satellite showing it in the gravity gradient stabilization mode with the SNAP-9A RTG mounted at the aft end. Figure 4 is a photograph of a SNAP-9A RTG.

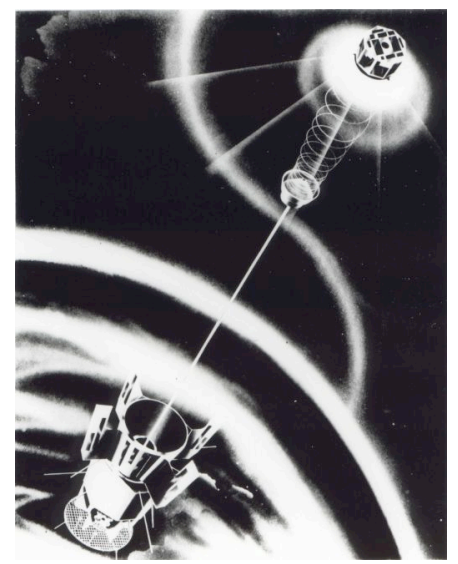

Figure 3. Artist's illustration of the Transit 5BN-1 navigational satellite. (Ref. 6)

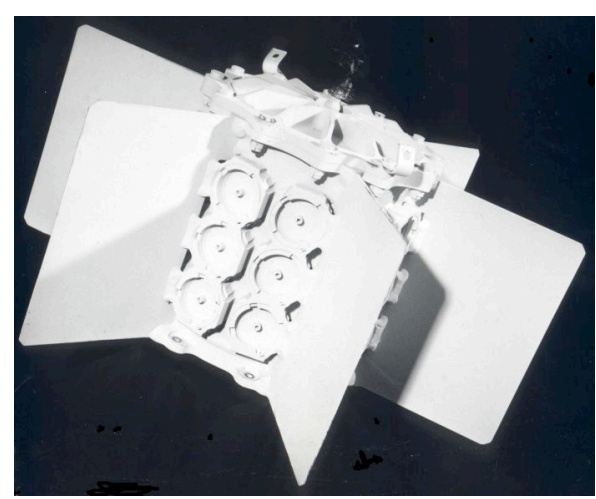

Figure 4. SNAP-9A RTG. The height was $26.7 \mathrm{~cm}$ and the fin span was $50.8 \mathrm{~cm}$. The power was $26.8 \mathrm{We}$ and the mass was $12.3 \mathrm{~kg}$. (Martin Nuclear)

\subsection{Transit TRIAD}

The TRIAD satellite (see Figure 5), which was launched on 2 September 1972 from VAFB, "was the first in a series of three experimental/operational spacecraft designed to flight test improvements to the Navy Navigation Satellite System". The principal power source was the Transit RTG (shown in Figure 6) which was to provide a minimum end-of-mission (EOM) power of $30 \mathrm{We}$ after five years at a minimum of $3 \mathrm{~V}$. Four solar-cell panels and a 6-Ah nickel-cadmium battery provided auxiliary power. ${ }^{9}$

The 13.6-kg Transit RTG used a SNAP-19 radioisotope heat source (see Section 4) coupled with light-weight thermoelectric panels using lead-telluride technology. In effect, the heat source radiated to the panels so the RTG did not have to be sealed. ${ }^{9}$

JHU/APL reported that "All TRIAD satellite and space technology experiments were exercised and the TRIAD short term objectives were demonstrated". 6 While a telemetry loss about a month into the mission precluded measuring the Transit RTG power the functioning of various TRIAD experiments showed that the Transit RTG more than met its objective. ${ }^{6}$ 


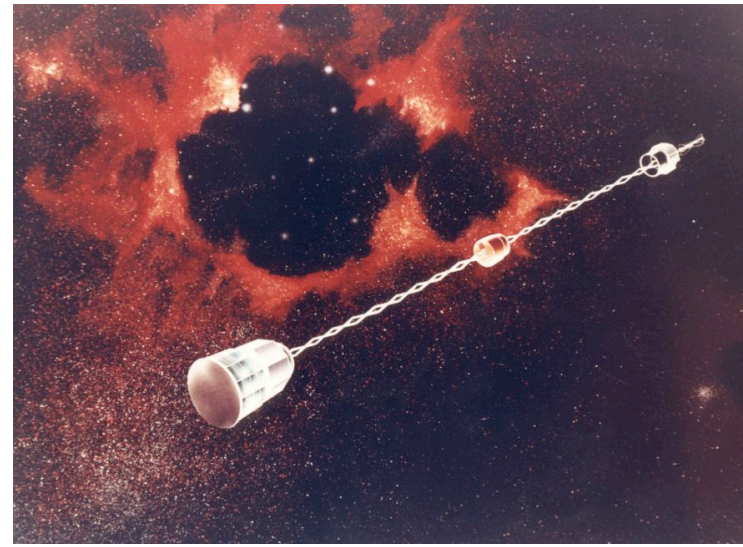

Figure 5. Transit TRIAD satellite in orbit (artist's conception). The TRANSIT RTG is at the lower left.

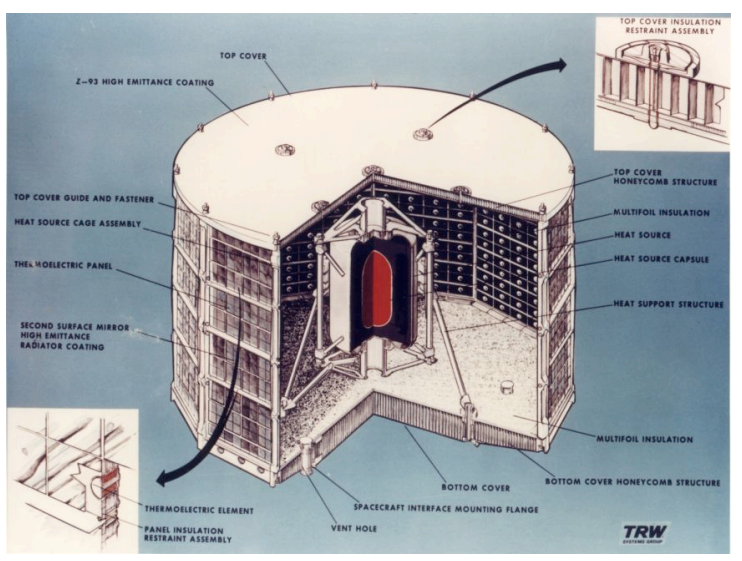

Figure 6. Cutaway of the TRANSIT RTG. The RTG was approximately $36.3 \mathrm{~cm}$ high by $61 \mathrm{~cm}$ across the flats. The TRANSIT RTG produced $35.6 \mathrm{We} \mathrm{BOM}$ with a mass of $13.6 \mathrm{~kg}$. (TRW/GA/AEC)

\section{SNAPSHOT Space Reactor Experiment}

The first nuclear reactor to be employed in space was launched by the U.S. Air Force from VAFB on 3 April 1965. The reactor, which was designated SNAP-10A, built upon the heritage of the earlier SNAP reactor programs, in particular, SNAP-2 and SNAP-10. SNAPSHOT, as the experiment was named, was a test of the operability of an automated space reactor. The power requirement for the $435-\mathrm{kg}$ SNAP-10A was to produce at least $500 \mathrm{We}$ for one year. ${ }^{10}$ Figure 7 is an artist's conception of the SNAP-10A reactor coupled to the Agena "spacecraft".

Once in its $1288-\mathrm{km}$ by $1307-\mathrm{km}$ nuclear safe orbit the reactor was started up and operated. All went well for 43 days until a failure of a voltage regulator in the Agena "spacecraft" caused a termination of the power operation. Nevertheless, SNAP-10A showed that it was feasible to remotely operate a liquid-metal-cooled nuclear reactor in space. The capability of SNAP-10A to operate unattended for one year was demonstrated in a ground-test twin to the flight reactor. ${ }^{10}$

Figure 7. SNAP-10 in orbit attached to the Agena bus. (Artist's concept) The overall length was $3.48 \mathrm{~m}$ and the mounting base diameter was $1.27 \mathrm{~m}$. The total system mass of the final flight unit was $435 \mathrm{~kg}$. SNAP-10A was designed to produce at least $500 \mathrm{We}$ for one year. (AI/AEC)

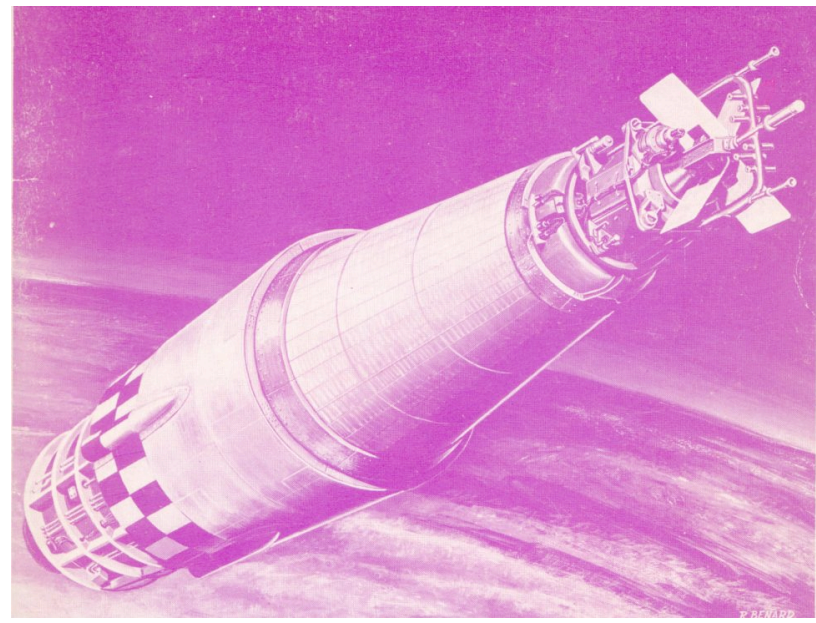




\section{Nimbus-3 Meteorological Satellite}

The SNAP-9A development program moved on to the SNAP-19 technology improvement program which became the basis for NASA's first outerplanetary missions. First, though, came the checkout on NASA's Nimbus-3 meteorological satellite which was launched on 14 April 1969 from VAFB. Nimbus-3 was the first U.S. weather satellite to make day and night global measurements from space of temperatures at varying levels in the atmosphere. Figure 8 is an artist's conception of the Nimbus-3 meteorological satellite showing two SNAP-19 RTGs mounted to the base platform. In addition to the two SNAP-19 RTGs, Nimbus-3 carried solar arrays.

The requirement on the two SNAP-19 RTGs was to deliver 50 We to the regulated-power bus after one year in orbit. The two 13.4-kg RTGs produced a combined $56.4 \mathrm{We}(49.4 \mathrm{We}$ usable) at launch and $47 \mathrm{We}$ one year later. This nuclear power comprised about 20 percent of the total power delivered to the regulated-power bus during that time, allowing a number of extremely important atmospheric-sounder experiments to operate in a full-time duty cycle. Without the RTGs, the total delivered power would have fallen below the load line about two weeks into the mission. ${ }^{11,12}$

Figure 8. Nimbus-3 in orbit (artist's concept). The two SNAP-19 RTGs are shown mounted on the left. The RTGs had a height of $26.7 \mathrm{~cm}$ and a fin span of $53.8 \mathrm{~cm}$. The average power per RTG was 28.2 We with a mass of $13.4 \mathrm{~kg}$. (NASA)

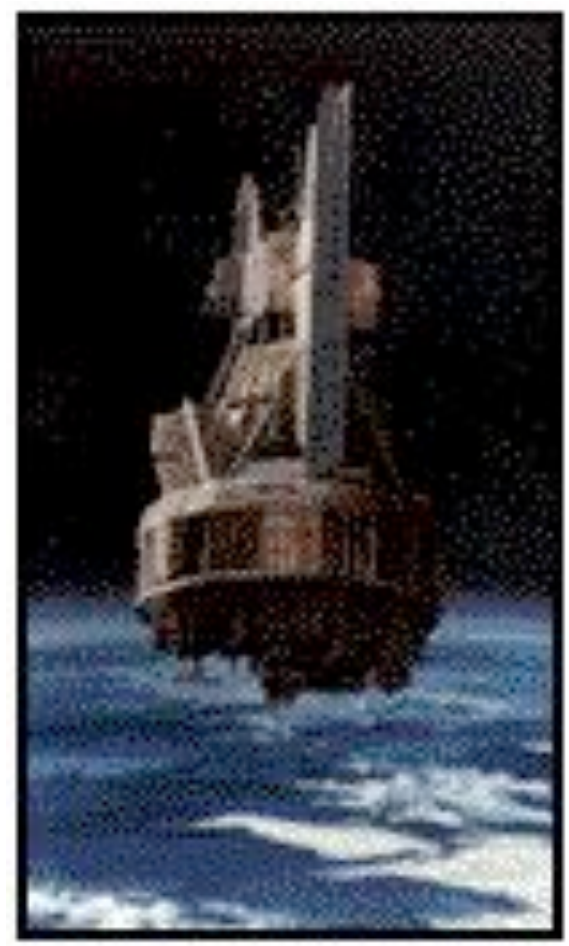

\section{Apollo Lunar Surface Experiments Packages}

Nuclear power on the Moon provides a number of important advantages, chiefly, the ability to deliver fullpower throughout the long (14-Earth-day) lunar night. This was one of the factors which led NASA to select RTG power for its Apollo Lunar Surface Experiments Packages (ALSEPs). The program objectives included acquiring scientific data to aid in determining the internal structure and composition of the Moon and the composition of the lunar atmosphere. ${ }^{13}$

Five ALSEPs were placed on the Moon, beginning with the Apollo 12 mission (see Figure 9) whose ALSEP downlink acquisition started on 19 November 1969. The Apollo $11 \mathrm{crew}$ deployed a forerunner of ALSEP, known as the Early Apollo Scientific Experiment Package (EASEP). The EASEP used solar cells for power and two 15-Wt radioisotope heater units (RHUs) for warmth. ${ }^{13}$ 
Power for each ALSEP was provided by a new RTG designated SNAP-27 (see Figure 10). The power requirement for the 19.6-kg RTG was to provide at least $63.5 \mathrm{We}$ at $16-\mathrm{V} \mathrm{DC}$ for one year after lunar emplacement. (For Apollo 17, the requirement was 69 We two years after emplacement.) ${ }^{14}$ All five ALSEP SNAP-27 RTGs (Apollo 12, 14, 15, 16, 17) exceeded their mission requirements in both power and lifetime which enabled the ALSEP stations to gather long-term scientific data on the Moon. ${ }^{13}$

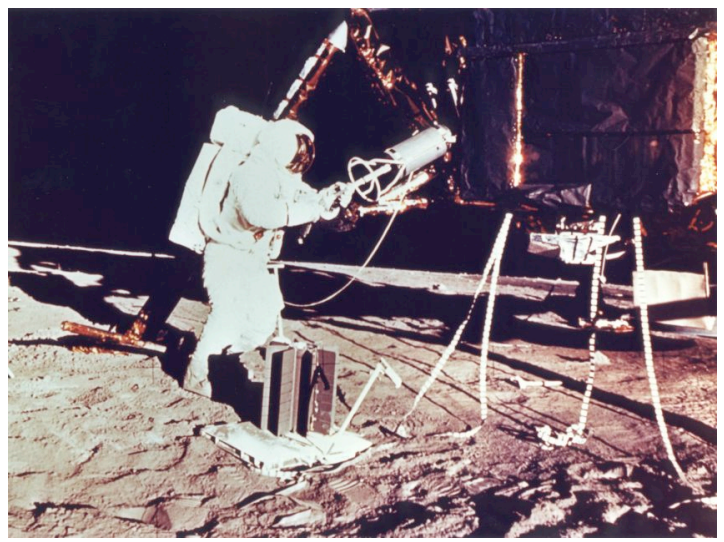

Figure 9. Alan Bean removing the SNAP-27 on the Apollo 12 mission in November 1969. (NASA)

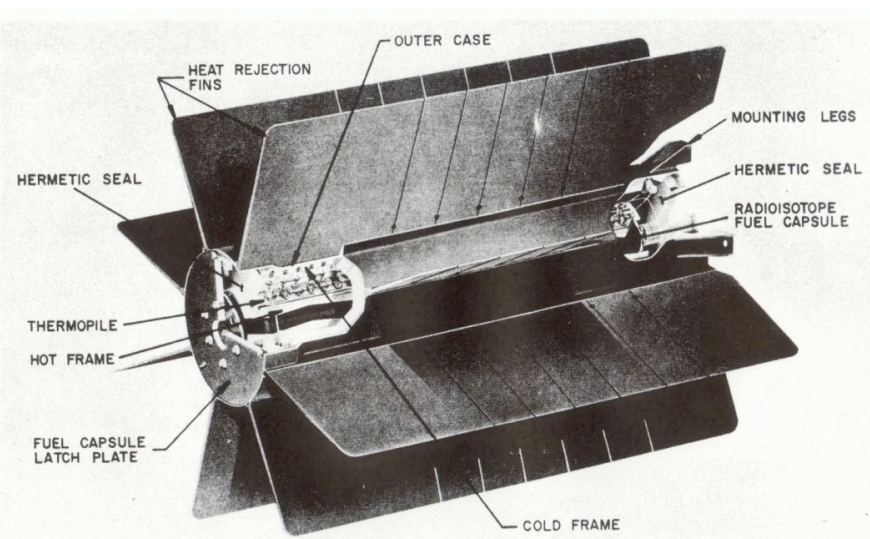

Figure 10. Cutaway of the SNAP-27 RTG.

The converter was $46 \mathrm{~cm}$ high and $40.0 \mathrm{~cm}$ across the fins. The RTG power was $\geq 63.5$ We with a mass of $19.6 \mathrm{~kg}$. (GE)

\section{Lincoln Experimental Satellites 8 and 9}

Lincoln Experimental Satellites 8 and 9 (LES-8/9), which were built for the U.S. Air Force, "were developed with the goal of demonstrating, in full-scale operation (terminals as well as satellites), advanced technologies for strategic communications links" (see Figure 11). ${ }^{15}$ Each spacecraft was powered by two RTGs of a completely new design (see Figure 12). Termed "Multi-Hundred Watt Radioisotope Thermoelectric Generator" (MHW-RTG), these RTGs were being developed for multiple missions; however, the initial focus was on NASA's Grand Tour (later Voyager) mission. With minimal modifications, the MHW-RTGs were used on LES-8/9 because they "offer impressive advantages of physical survivability by comparison with solar-cell arrays". ${ }^{15}$

For LES-8/9, each 39.69-kg MHW-RTG was to produce $125 \mathrm{We}$ at $26 \mathrm{~V}$ at the end of mission - an operational life of at least five years after launch (which occurred on 14 March 1976). ${ }^{16}$ (BOM powers averaged about $154 \mathrm{We}$ per RTG.) The MHW-RTGs more than met this goal. LES-8 was turned off on 2 June 2004 because of control difficulties (its two MHW-RTGs were still providing usable electrical power). LES-9 continues to operate over 30 years after launch!

Writing 13 years after the launch, two of the LES-8/9 managers concluded, "The RTGs were well worth the effort ... they have performed superbly. They provide continuous electrical power through the 70-min eclipses of the sun by the earth that LES- 8 and LES-9 experience every day. The compatibility of these rugged power sources with complex signal-processing circuitry has been well established. ... the measures that were taken to assure the success of the RTGs in LES-8 and-9 contributed directly to the success of the Voyager missions". ${ }^{17}$ 


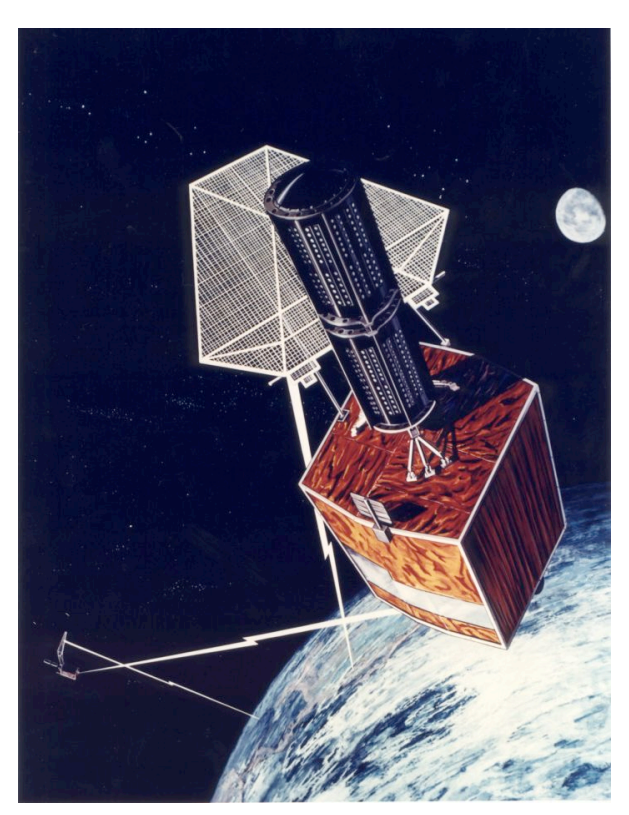

Figure 11. LES-8 and LES-9 in orbit. The two MHW-RTGs are shown mounted on top of one of the satellites.

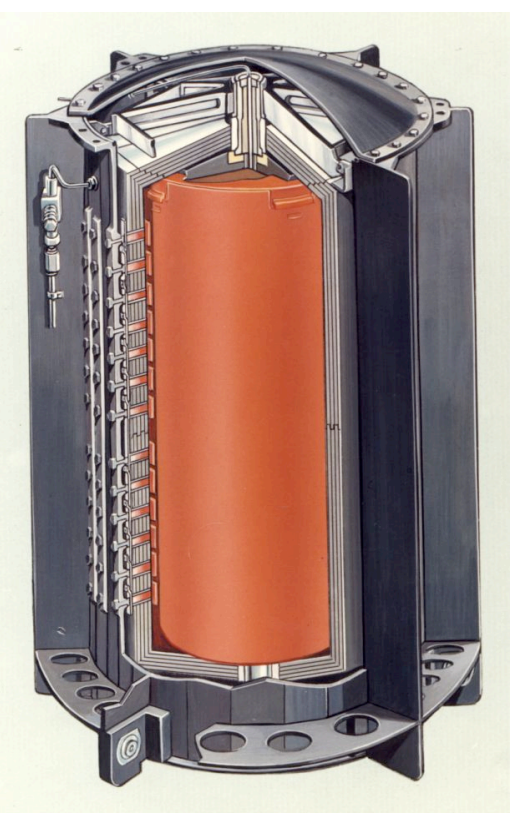

Figure 12. Cutaway of the MHW-RTG. The length was $58.31 \mathrm{~cm}$ and the overall diameter was $39.73 \mathrm{~cm}$. For LES-8/9 the average BOM power was $\sim 154 \mathrm{We}$ per RTG with a mass of $39.69 \mathrm{~kg}$ (avg.). For Voyager $1 / 2$ the average BOM power was $\sim 158 \mathrm{We} / \mathrm{RTG}$ with a mass of $37.69 \mathrm{~kg}$ (average). (GE)

\section{Interplanetary Missions}

From a public standpoint, the most spectacular uses of nuclear power sources in space have come from the interplanetary missions, beginning with the launches of the Pioneer 10 and Pioneer 11 spacecraft in 1972 and 1973 respectively. When a spacecraft is sent where the sunlight is low (at Jupiter: 25 times less than at Earth; at Pluto: $>900$ times less than at Earth), where the temperatures are quite low $(\sim 130 \mathrm{~K}$ at Jupiter) and where the radiation belts are very severe the only option is nuclear power. This section summarizes the RTG performance on U.S. interplanetary missions from the Pioneers (Jupiter, Saturn) to the Vikings (Mars), Voyagers (Jupiter, Saturn, Uranus, Neptune), Galileo (Jupiter), Ulysses (solar polar), and Cassini (Saturn) to the most recent, the New Horizons mission to Pluto.

\subsection{Pioneers 10 and 11}

Pioneers 10 and 11 were built to explore the environment of Jupiter as well as the interplanetary medium beyond the orbit of Mars and the asteroid belt. Pioneer 10 was launched on 2 March 1972 on a fast trajectory to Jupiter (closest approach on 3 December 1973). The twin spacecraft Pioneer 11 was launched on 5 April 1973 to follow Pioneer 10 to Jupiter (closest approach on 4 December 1974).

Each Pioneer spacecraft carried four 13.6-kg SNAP-19 RTGs, producing an average of $40.3 \mathrm{We}$ per RTG at BOM. The mission requirement was that the four SNAP-19 RTGs on each Pioneer spacecraft had to produce 120 We total at the Jupiter flyby. The RTGs more than met this requirement which enabled NASA to direct Pioneer 11 on for a first encounter with Saturn (closest approach on 1 September 1979). The Pioneer 11 SNAP-19 RTGs exceed the $90 \mathrm{We}$ required at Saturn by producing $119.3 \mathrm{We}$. By this time the RTGs on both spacecraft had operated well beyond their original 21-month requirement. ${ }^{18}$ (Both Pioneer spacecraft also carried a number of small radioisotope heater units, RHUs, to keep equipment warm without the potential electromagnetic interference of electrical heaters.) 
Both spacecraft continued to operate for decades after their original mission objectives had been met and so gave scientists a wealth of information on the interplanetary medium in the outer Solar System. The last signal from Pioneer 10 was received on 22 January 2003, more than 30 years after launch! (The last signal from Pioneer 11 was received on 30 September 1995.) Figure 13 is an artist's illustration of Pioneer 10 and Figure 14 is a cutaway of the Pioneer SNAP-19 RTG.

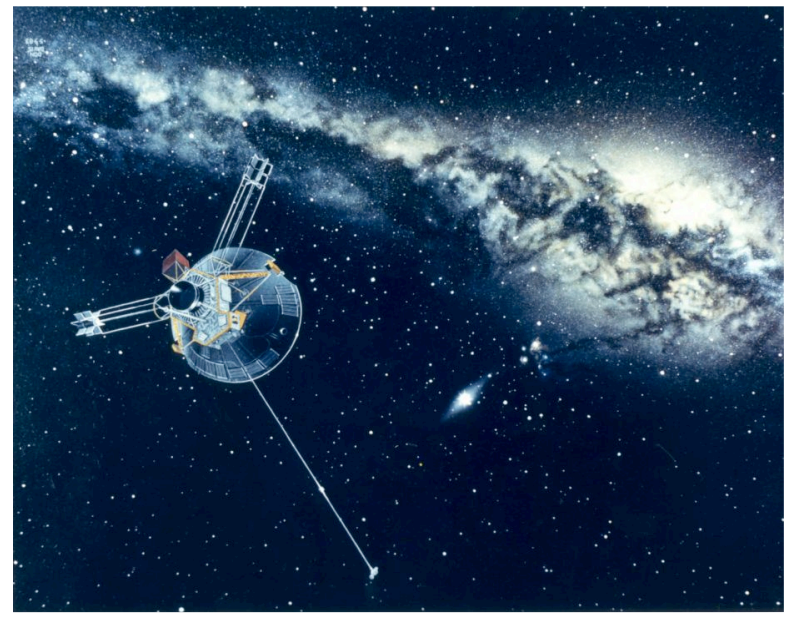

Figure 13. Pioneer 10 leaving the Solar System. (Artist's concept). (NASA)

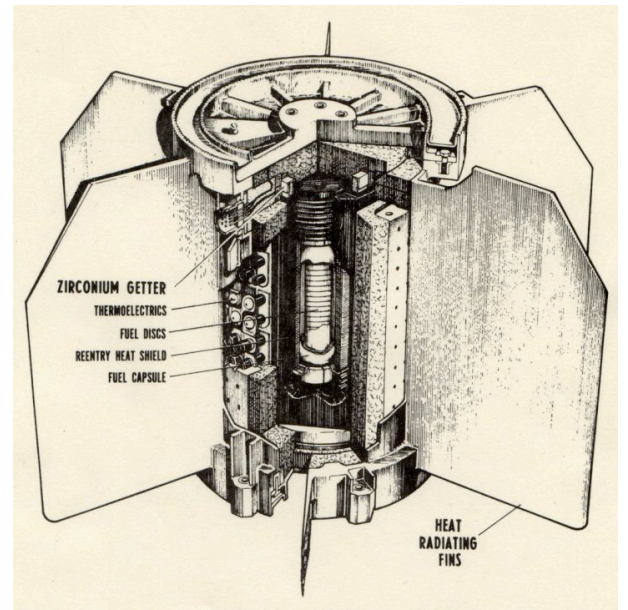

Figure 14. Cutaway of the Pioneer SNAP-19 RTG. The height was $28.2 \mathrm{~cm}$ and the fin span $=50.8 \mathrm{~cm}$. The average BOM power was 40.3 We per RTG. (TES)

\subsection{Viking Landers 1 and 2}

In 1975, the U.S. embarked on the first surface exploration of Mars with the launches of the two Viking missions. Each Viking spacecraft consisted of an Orbiter and a Lander. In view of the hostile environment of Mars (including dust storms and Antarctic-style temperatures), NASA selected a modified SNAP-19 RTG to power the Viking Landers (two RTGs per Lander). The modifications included the addition of a dome for gas exchange with the main body of the RTG. The average BOM power of these $15.2 \mathrm{~kg}$ RTGs was $42.7 \mathrm{We}$ per RTG. The requirement was to produce a minimum of $35 \mathrm{We}$ during the 90 -day primary mission. ${ }^{18,19}$ Figure 15 shows how the SNAP-19 RTGs were placed on a Viking Lander. Viking 1 was launched on 20 August 1975 and its Lander reached the Martian surface on 20 July 1976. Viking 2 was launched on 9 September 1975 and its Lander reached the Martian surface on 3 September 1976.

Figure 15. Model of the Viking Mars Lander showing the locations of the two Viking SNAP-19 RTGs. The RTGs had a height of $40.4 \mathrm{~cm}$ and a fin span of $58.7 \mathrm{~cm}$. The average BOM power per RTG was $42.7 \mathrm{We}$ and the average mass was $15.2 \mathrm{~kg}$ per RTG. (NASA/TES)

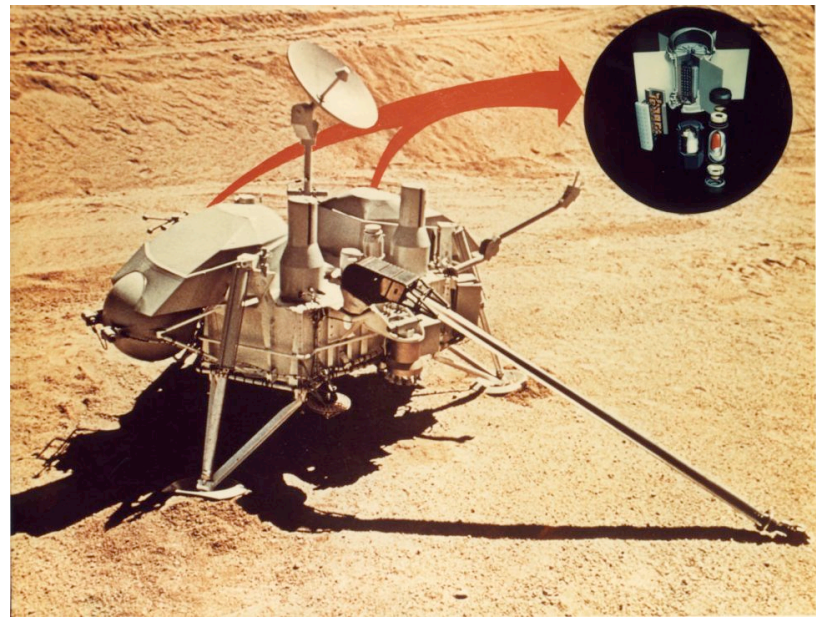


All four SNAP-19 RTGs easily met the 90-day requirement allowing the Viking Landers to operate for years until other system failures led to a loss of data. When the last data were received from Viking Lander 1 in November 1982, it had been estimated that the RTGs were capable of providing sufficient power for operation until 1994 - 18 years beyond the original mission requirement. Had an accidental shutdown not occurred, it is fascinating to speculate if Viking Lander 1 might have been ready to greet Mars Pathfinder when it landed on 4 July 1997 !

As an aside, it is worth noting that all three U.S. Mars rovers (Pathfinder, Opportunity, and Spirit) carried 1-Wt light-weight radioisotope heater units (LWRHUs) to keep them warm during the cold Martian nights.

\subsection{Voyager 1 and Voyager 2}

Following on the paths of Pioneers 10 and 11, the more advanced Voyager 1 and Voyager 2 spacecraft were launched in 1977 to conduct more detailed studies of Jupiter and Saturn, their satellites and magnetospheres as well as studies of the interplanetary medium. The successful completion of the Saturn flybys allowed NASA to send Voyager 2 on to the first flybys of Uranus and Neptune, completing most of the objectives for the originally planned Grand Tour mission.

To power these two spacecraft so far from the Sun, the Voyagers used Multi-Hundred Watt Radioisotope Thermoelectric Generators (MHW-RTGs) similar in design to those flown the year before on the U.S. Air Force communications satellites LES-8/9 (see Fig. 12 for LES-8/9 version). With some modifications, the MHW-RTG mass was reduced to an average of $37.69 \mathrm{~kg}$. The Voyager mission required an EOM minimum power of $128 \mathrm{We}$ per RTG four years after launch. BOM powers averaged about $158 \mathrm{We}$ per RTG. ${ }^{2,3}$ (Both Voyager spacecraft also carried a number of small radioisotope heater units, RHUs, to keep equipment warm.)

The two Voyager spacecraft (see Figure 16) have probably explored more territory than any other spacecraft in human history. Discoveries ranged from finding 22 new satellites (3 at Jupiter; 3 at Saturn; 10 at Uranus; and 6 at Neptune) to witnessing the first volcanic eruption on another Solar System body (Io) and geysers on another satellite (Triton). The two Voyager spacecraft are now operating in an interstellar mode where they continue to provide new information beyond the orbit of Pluto.

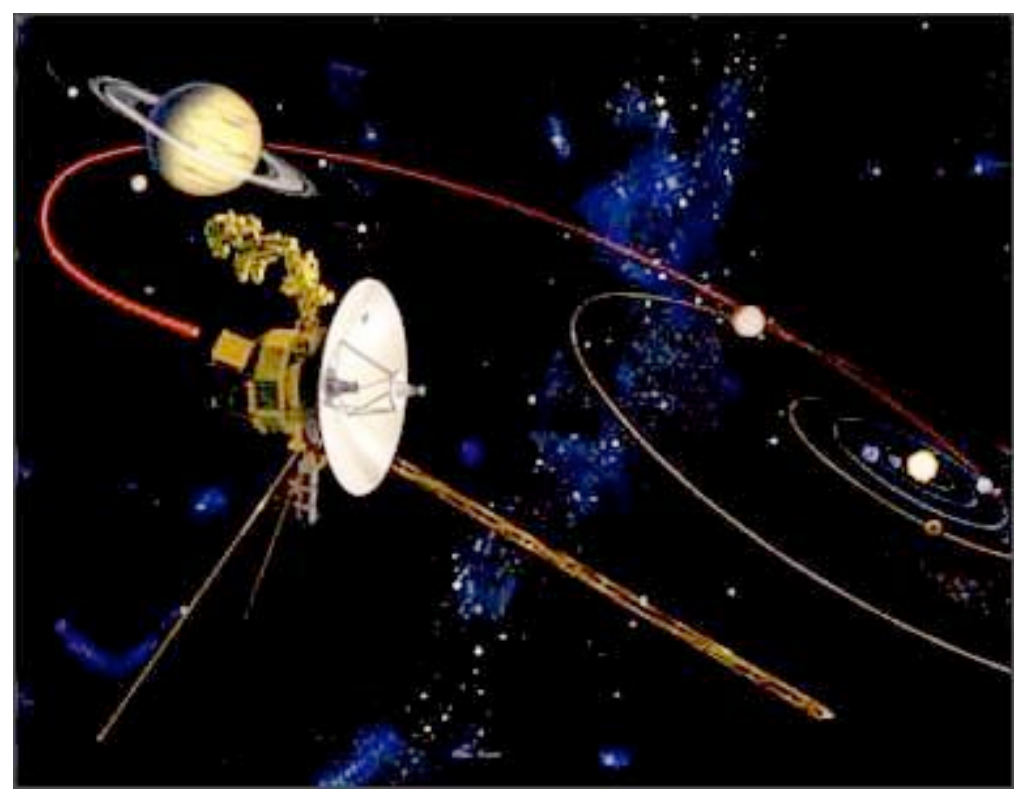

Figure 16. Artist's concept of the path of a Voyager spacecraft past Jupiter and Saturn. The three MHW-RTGs are shown mounted below the spacecraft on a boom. 


\subsection{Galileo}

With the completion of the successful Pioneer and Voyager flybys scientists turned to an in-depth study of the largest planet in the Solar System. Conceived at the time of the Voyager launches, the Galileo spacecraft was launched on 18 October 1989 on a series of gravity assist maneuvers to take this technologically sophisticated Orbiter and atmospheric Probe to Jupiter. There Galileo investigated the Jovian atmosphere; the Jovian satellites; the Jovian magnetosphere; and energetic particles and plasma.

Powering Galileo in this hostile environment were two new RTGs designated by the acronym GPHS-RTG (General-Purpose Heat Source Radioisotope Thermoelectric Generator). At the time of fueling (beginning-of-life, BOL), a GPHS-RTG is capable of producing about $300 \mathrm{We}$ in a mass envelope of about $55.9 \mathrm{~kg}$ making this the highest specific power nuclear power source ever flown by the U.S. Because of launch delays caused by the Challenger accident, the power requirement for the Galileo GPHS-RTGs was changed to $470 \mathrm{We}$ (235 We per RTG) at end-of-mission (EOM) $\left(71,000 \mathrm{~h}\right.$ after BOM) ${ }^{20}$ The combined BOM power of the two GPHS-RTGs was 577.2 We. ${ }^{21}$ Galileo went into orbit on 7 December 1995 as the Probe entered the atmosphere of Jupiter. Figure 17 is an artist's conception of the Galileo spacecraft at Jupiter and Figure 18 illustrates the features of the GPHS-RTG. Both the Galileo Orbiter and Probe carried new, lower-mass 1-Wt radioisotope heater units (RHUs), which were termed the light-weight radioisotope heater unit or LWRHU.

Both GPHS-RTGs met their EOM power requirements allowing NASA and JPL to extend the Galileo mission three times. Finally, on 21 September 2003, after 35 orbits of Jupiter and with its propellant running low, Galileo was sent into the atmosphere of Jupiter so that it would not collide with the oceanic satellite Europa. In its 14-year life, Galileo sent back data on Earth, Venus, two asteroids (Gaspra and Ida and its moon Dactyl) and the Jovian system plus views of comet Shoemaker-Levy 9 crashing into Jupiter. Galileo also sent the first atmospheric probe into the atmosphere of a giant planet, a probe kept warm with LWRHUs.

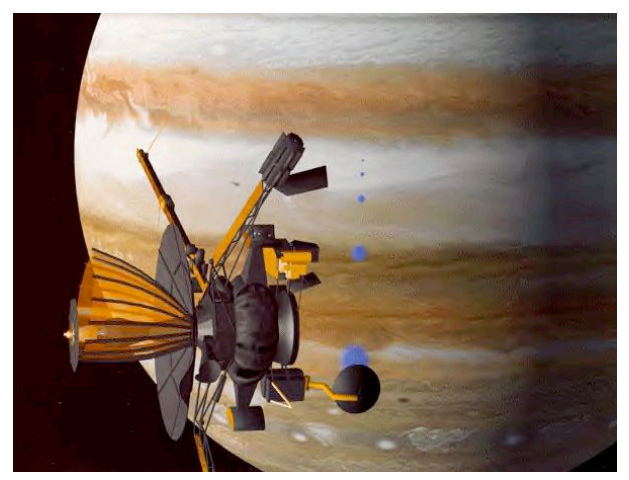

Figure 17. Galileo Orbiter communicating with the Galileo Probe. One of the two GPHS-RTGs is shown on a boom "above" Galileo. (NASA/JPL)

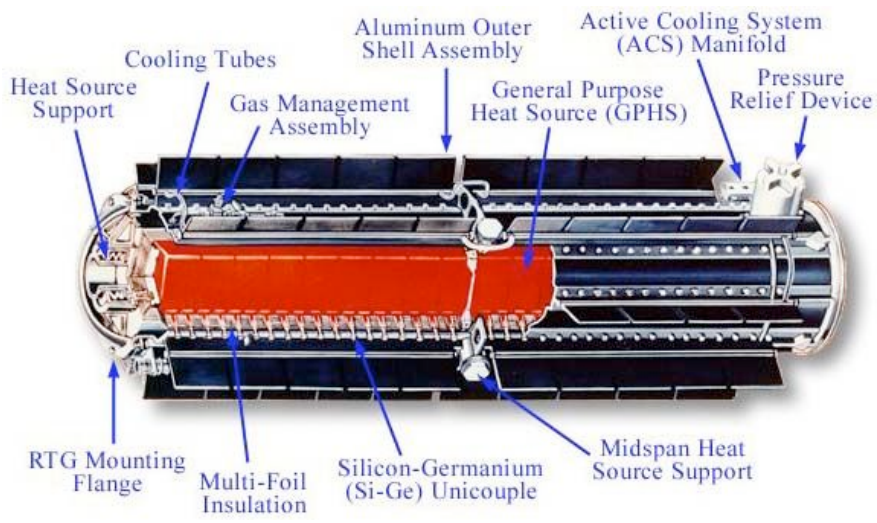

Figure 18. Cutaway of the GPHS-RTG.

The length is $114 \mathrm{~cm}$ and the fin span is $42.2 \mathrm{~cm}$. At time of fueling, the GPHS-RTG can produce $300 \mathrm{We}$. For Galileo and Ulysses the average RTG mass $=55.9 \mathrm{~kg}$. (LMA/DOE)

\subsection{Ulysses}

Originally planned as part of a two-spacecraft mission, the Ulysses spacecraft was launched on 6 October 1990 "to investigate, as a function of solar latitude, the properties of the solar wind and the interplanetary magnetic field, of galactic cosmic rays and neutral interstellar gas, and to study energetic particle composition and acceleration" (http://nssdc.gsfc.nasa.gov/). Even though Ulysses is essentially a solar polar mission, it needed the immense gravity of Jupiter to bend its orbit out of the plane of the ecliptic. These regular trips out to five astronomical units (along with the Jovian radiation belts) dictated a nuclear power source (GPHS-RTG) for Ulysses. 
The Ulysses GPHS-RTG power requirements were modified because of the over four-year delay following the Challenger accident: provide a beginning-of-mission (BOM) power of $277 \mathrm{We}$ and an end-of-mission (EOM) power $(42,000 \mathrm{~h})$ of $245 \mathrm{We}^{20}$ Telemetry measurements indicated a BOM power of $284 \mathrm{We}$ at the bus and $289 \mathrm{We}$ at the RTG connector, both in excess of the minimum required. The August 1995 "EOM" was reported to be 248 We, three watts above the minimum. ${ }^{21}$ Because of the excellent performance of the Ulysses GPHS-RTG, the mission has been extended several times. In November 2006, Ulysses will start its third south polar pass. The currently projected end-of-mission is March 2008 after Ulysses completes its third north polar pass. In this time Ulysses has returned a wealth of information on the latitudinal distribution of particles and fields from our closest star.

Figure 19 is an artist's illustration of the Ulysses mission showing its GPHS-RTG mounted on the side of the main body of the spacecraft.

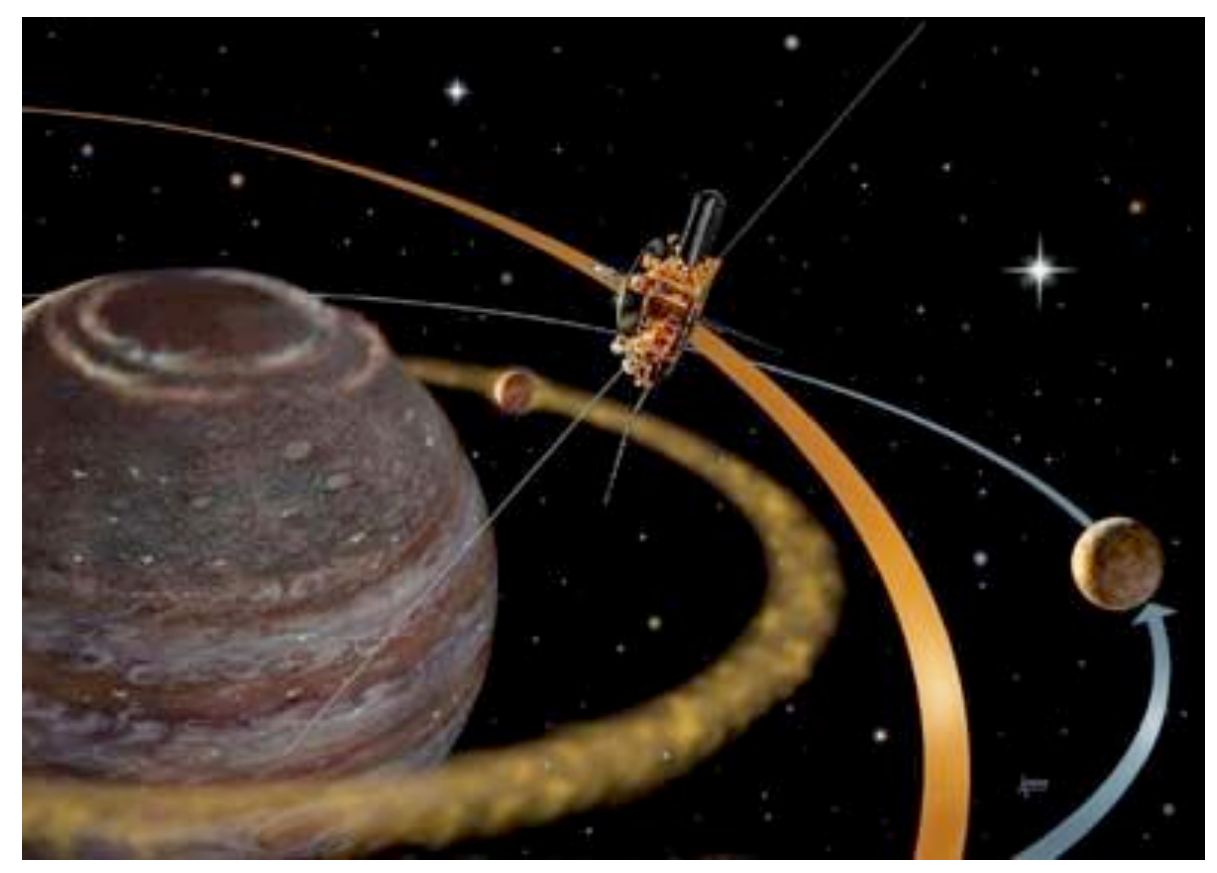

Figure 19. Ulysses spacecraft shown in its second Jupiter encounter (November 2003 - April 2004). The GPHS-RTG is shown mounted on "top" of the spacecraft. (NASA/ESA/JPL).

\subsection{Cassini}

Following on the successful Pioneer and Voyager flybys of Saturn, scientists turned next to an orbiter/probe mission to provide a more in-depth study of the ringed world. On 15 October 1997, the Cassini spacecraft was launched to do, in a sense, what Galileo had done at Jupiter: carryout a multi-year scientific study of the second largest gas giant in the Solar System. Mission objectives included studying the rings, the satellites, the magnetosphere, and, in particular, Titan, the cloud-covered largest satellite of Saturn. Like Galileo, Cassini carried a probe (Huygens), this one built by the European Space Agency (ESA) and designed to land on Titan.

Cassini successfully went into orbit around Saturn in July 2004 after traveling past Venus, Earth, and Jupiter. Huygens, which carried Galileo-style light-weight radioisotope heater units (LWRHUs) to keep it warm, successfully landed on Titan and provided dramatic views of that shrouded world. Cassini is now well into its fouryear main mission of 74 orbits around Saturn with 44 flybys of Titan. 
Because of mission complexity, Cassini needed more power than used on previous missions of this type. Three modified GPHS-RTGs provide that power. The specification requirement for BOM was $826 \mathrm{We}$. The three GPHSRTGs provided $887 \mathrm{We}$ total at BOM. The average mass per RTG is $56.4 \mathrm{~kg}$. The projected power at 16 years after BOM is $640 \mathrm{We}$ which will exceed the specification requirement of $596 \mathrm{We}^{21}$ The prognosis is excellent that the Cassini RTGs will provide sufficient power for an extended mission beyond the main mission. Figure 20 is an artist's illustration of the Cassini spacecraft showing two of the three GPHS-RTGs. Cassini also carried LWRHUs to keep equipment warm.

Figure 20. Cassini shown over Titan as the Huygens probe descends toward Titan. (Artist's concept) Two of the three GPHS-RTGs are shown mounted at the "upper end" in this figure. (NASA/JPL)

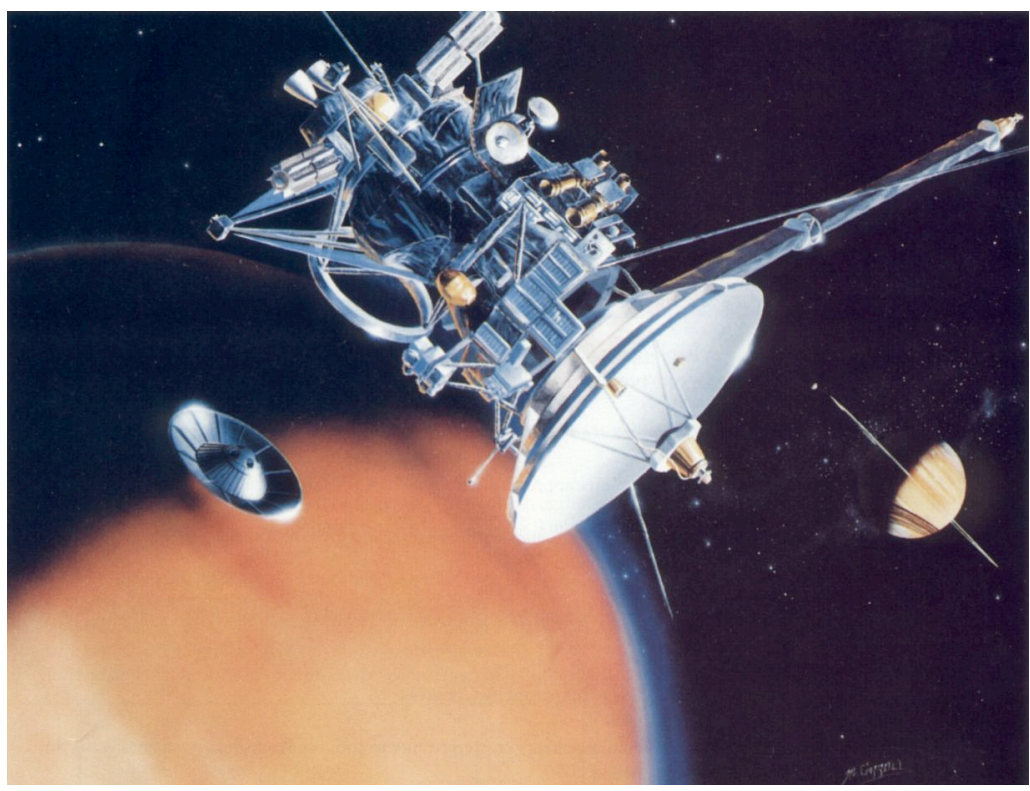

\subsection{New Horizons Pluto Kuiper Belt Flyby}

One planet remained unexplored after the Pioneer and Voyager flyby missions: Pluto, once thought to be the "last planet". On 19 January 2006, the New Horizons spacecraft was launched to fly by Pluto and its moon Charon. New Horizons will then continue on into the Kuiper Belt where it will fly by one or more Kuiper Belt Objects (KBOs). On its way to the Pluto/Charon system, New Horizons will fly by Jupiter in late February 2007 for a gravity assist. During that four-month encounter period, New Horizons will study Jupiter, adding to our knowledge of the Solar System's largest planet.

New Horizons is expected to fly by Pluto on 14 July 2015 (see Figure 21). From about 2016 to 2020, following the Pluto/Charon flyby, New Horizons will enter the Kuiper Belt Object study phase of the mission.

In a region of space where the sunlight is less than 0.001 of what it is at Earth, nuclear power is the only viable option. Thus, New Horizons carries a single GPHS-RTG to provide power in the far reaches of the Solar System. With various modifications (including changes to the heat source modules) the flight mass is $57.8 \mathrm{~kg}$. The beginning-of-mission power from this GPHS-RTG was 245.7 We versus a specification requirement of 237 We. This power was lower than what has been produced in the GPHS-RTGs flown on earlier missions primarily because the New Horizons GPHS-RTG used some older fuel that had decayed for over 21 years. ${ }^{22,23}$ Still, it is expected that the GPHS-RTG will produce about $200 \mathrm{We}$ (versus the specification minimum of $191 \mathrm{We}$ ) at the time of Pluto/Charon flyby, enough for New Horizons to conduct exciting scientific studies of what was once thought to be our farthest planet. ${ }^{23}$ 


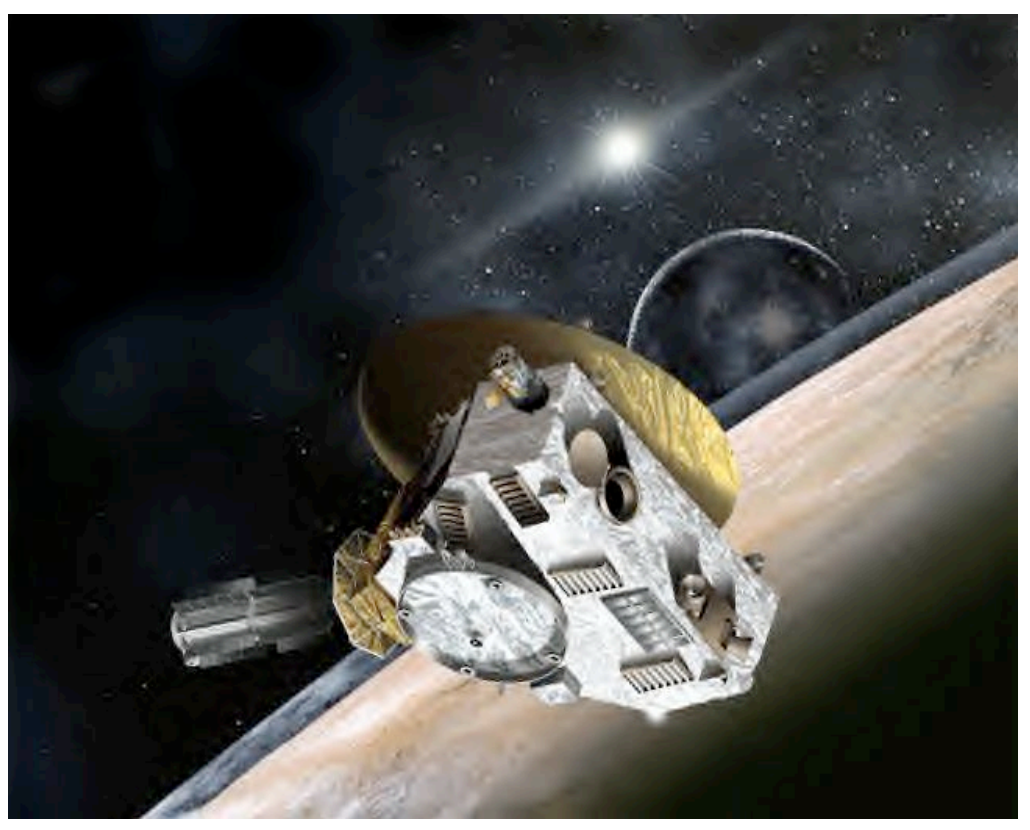

Figure 21. New Horizons flying over Pluto with Charon in the background. The GPHS-RTG is shown mounted on the left side in this illustration. (JHU/APL; SwRI)

\section{Russian Space Nuclear Power Sources}

The former Soviet Union also had an active space nuclear program, launching about 31 (and perhaps 33) BUK space nuclear reactors to power spacecraft used for marine radar observations. The BUK liquid-metal-cooled fast reactor produced about $3 \mathrm{kWe}$ from $100 \mathrm{kWt}$ of thermal power using two-stage thermoelectric elements. Launches of BUK may have begun as early as 1967 with the last publicly known launch occurring in $1988 .^{24,25}$

In 1987, the former Soviet Union launched two experimental thermal reactors designated TOPAZ. These experimental reactors, which used an in-core thermionic conversion system, reportedly produced about $5 \mathrm{kWe}$ from a reactor thermal power of $150 \mathrm{kWt}^{24,25}$ In the late $1980 \mathrm{~s}$ and early $1990 \mathrm{~s}$, certain elements of the U.S. Department of Defense (DoD) showed some interest in testing and flying another Russian thermionic reactor (ENISEY) that had not been flown by the Russians. ${ }^{24}$ In the U.S., this reactor was erroneously dubbed "TOPAZ 2" (but it was not built by the Russian group which had built TOPAZ).

In addition to nuclear reactors, the former Soviet Union has used radioisotope heater units (RHUs) and small RTGs on some missions. ${ }^{25}$

\section{Space Nuclear Safety}

The main design requirement on U.S. space nuclear power systems is and has been safety. From the very first systems (SNAP-3B), extensive safety testing and analyses have been conducted. Formal safety analysis reports and independent safety reviews are required before each launch. ${ }^{26}$ With the enactment of the National Environmental Policy Act in 1969, an independent environmental assessment is also conducted. ${ }^{26}$

For radioisotope power sources, the primary safety requirement is to contain or immobilize the radioisotope fuel so that there is no interaction with humans and the environment. Designs are assessed through a combination of safety tests (often involving explosions, projectiles, fires, and impacts) and analyses. ${ }^{26}$ 
For space nuclear reactors, the primary safety requirement is to maintain the reactor in a subcritical condition under postulated accident conditions (such as explosions, projectiles, fires, water immersion, and impacts). For the one U.S. space nuclear reactor flown (SNAP-10A in 1965), extensive safety tests and analyses were conducted. ${ }^{10,26}$

Thanks to this rigorous safety program, all three U.S. RTG-powered missions involved in accidents met their safety design requirements and posed no threat to people. [The three missions were Transit 5BN-3 (21 April 1964); Nimbus-B1 (18 May 1968); and Apollo 13 (17 April 1970).] The accidents were not caused by the RTGs. ${ }^{26}$

The Russians have reportedly had two reentries of nuclear reactors (Cosmos 954 and Cosmos 1402) and three reentries of radioisotope systems (Cosmos 300, Cosmos 305, and Mars-96). The Russians have reported that these systems met their requirements. ${ }^{27}$

\section{Conclusions}

For almost 45 years, space nuclear power sources have proved to be safe, reliable, sturdy, long-lived sources of electrical power. Since 1961, the U.S. has successfully launched 42 nuclear power sources (41 radioisotope thermoelectric generators and one nuclear reactor) on 24 space missions along with hundreds of radioisotope heater units (RHUs). The SNAP-10A space nuclear reactor power system demonstrated the viability of automatically controlled, liquid-metal-cooled reactors for space applications. The radioisotope thermoelectric generators have enabled some of the most challenging and scientifically exciting missions in human history, including the Apollo Lunar Surface Experiments Packages; the Pioneer flybys of Jupiter and Saturn; the Viking Mars Landers; the Voyager flybys of Jupiter, Saturn, Uranus, and Neptune; the Galileo orbital exploration of Jupiter; the Ulysses solar polar explorer; the Cassini orbital exploration of Saturn; and, most recently, the New Horizons mission to the Pluto/Charon system. In general, the RTGs, from the first SNAP-3Bs to the GPHS-RTGs have exceeded their mission requirements by providing power at or above that required and beyond the planned mission lifetime. Clearly space nuclear power has enabled the human race to enter the final frontier.

\section{Acknowledgments}

The author acknowledges a very deep debt of gratitude to the hundreds upon hundreds of dedicated people who have made U.S. space nuclear power a reality. In particular, the author acknowledges the outstanding contributions made by the staff members at Lockheed Martin Space Systems, Teledyne Energy Systems, Atomics International, TRW (now part of Northrop-Grumman), General Atomic, Johns Hopkins University Applied Physics Laboratory (JHU/APL), NUS Corporation, Orbital Sciences Corporation, Battelle Columbus Laboratories, MIT Lincoln Laboratory, Jet Propulsion Laboratory, 3M Company, RCA, Mound Laboratory, Savannah River Plant and Laboratory, Los Alamos National Laboratory, Oak Ridge National Laboratory, Sandia National Laboratories, Idaho National Laboratory, Ames Laboratory, and the associated NASA, U.S. Department of Defense (DoD) and U.S. Department of Energy (DOE) offices.

\section{References}

${ }^{1}$ Corliss, W. R. and Harvey, D. G., Radioisotopic Power Generation, Prentice-Hall, Inc., Englewood Cliffs, New Jersey, 1964.

${ }^{2}$ Bennett, Gary L., Lombardo, James J., and Rock, Bernard J., "U.S. Radioisotope Thermoelectric Generator Space Operating Experience (June 1961 - December 1982) in Proceedings of the $18^{\text {th }}$ Intersociety Energy Conversion Engineering Conference, held in Orlando, Florida, 21-26 August 1983. Reprinted in The Nuclear Engineer, Vol. 25, No. 2, pp. 49-58 (March/April 1984).

${ }^{3}$ Bennett, Gary L. and Skrabek, E. A., "Power Performance of U.S. Radioisotope Thermoelectric Generators" in Proceedings ICT '96, Fifteenth International Conference on Thermoelectrics, pp. 357-372, held in Pasadena, California, $26-29$ March 1996, IEEE Catalog Number 96TH8169, Library of Congress Number 96-75531.

${ }^{4}$ Bennett, Gary L., "Space Nuclear Power", in Encyclopedia of Physical Science and Technology, Third Edition, Volume 15, pp. 537-553, Academic Press, New York, 2002. 
${ }^{5}$ Wyatt, T., "The Gestation of Transit as Perceived by One Participant”, Johns Hopkins APL Technical Digest, Volume 2, Number 1, pp. 32-38, January-March 1981.

${ }^{6}$ Johns Hopkins University Applied Physics Laboratory, Artificial Earth Satellite Designed and Fabricated by the Johns Hopkins University Applied Physics Laboratory, JHU/APL Report SDO-1600 (revised), August 1980.

${ }^{7}$ Dick, P. J. and Davis, R. E., "Radioisotope Power System Operation in the Transit Satellite”, Paper No. CP 62-1173, AIEE Summer General Meeting, 17-22 1962, Denver, Colorado.

${ }^{8}$ Dick, P. J., SNAP-9A Quarterly Progress Report No. 2, Radioisotope-Fueled Thermoelectric Power Conversion System Development, December 1, 1961 through February 28, 1962, MND-P-2700-2, undated.

${ }^{9}$ Bradshaw, G. B. and Postula, F. D., "Beginning of Mission Flight Data on the TRANSIT RTG", Paper 739091, in Proceedings of the $8^{\text {th }}$ Intersociety Energy Conversion Engineering Conference, held in Philadelphia, Pennsylvania, 13-16 August 1973.

${ }^{10}$ Staub, D. W., SNAP 10A Summary Report, Atomics International Report NAA-SR-12073, 25 March 1967.

${ }^{11}$ Fihelly, A. W. and Baxter, C. F., "Orbital Performance of the SNAP-19 Radioisotopic Thermoelectric Generator Experiment", Paper 719152, in Proceedings of the $6^{\text {th }}$ Intersociety Energy Conversion Engineering Conference, held in Boston, Massachusetts, 3-5 August 1971.

${ }^{12}$ Jaffe, H. and O'Riordan, P., "Isotope Power Systems for Unmanned Spacecraft Applications", Paper 729088, in Proceedings of the $7^{\text {th }}$ Intersociety Energy Conversion Engineering Conference, held in San Diego, California, 25-29 September 1972.

${ }^{13}$ Bates, J. R., Lauderdale, W. W., and Kernaghan, H., ALSEP Termination Report, NASA Reference Publication 1036, 1979

${ }^{14}$ Pitrolo, A. A., Rock, B. J., Remini, W. C., and Leonard, J. A., "SNAP-27 Program Review" in Proceedings of the $4^{\text {th }}$ Intersociety Energy Conversion Engineering Conference, held in Washington, D.C., 22-26 September 1969.

${ }^{15}$ Ward, W. W., Developing, Testing, and Operating Lincoln Experimental Satellites 8 and 9 (LES-8/9), M.I.T. Lincoln Laboratory Technical Note 1979-3, 16 January 1979.

${ }^{16}$ Kelly, C. E., "The MHW Converter (RTG)", Paper 759132, Record of the $10^{\text {th }}$ Intersociety Energy Conversion Engineering Conference, held in Newark, Delaware, 18-22 August 1975.

${ }^{17}$ Ward,W. W. and Floyd, F. W., "Thirty Years of Research and Development in Space Communications at Lincoln Laboratory, The Lincoln Laboratory Journal, Vol. 2, No. 1, Spring 1989.

${ }^{18}$ Brittain, W. M. and Skrabek, E. A., "SNAP 19 RTG Performance Update for the Pioneer and Viking Missions", in Proceedings of the $18^{\text {th }}$ Intersociety Energy Conversion Engineering Conference, held in Orlando, Florida, 21-26 August 1983.

${ }^{19}$ Brittain, W. M., "SNAP-19 Viking RTG Mission Performance", Paper 769255 in Proceedings of the $11^{\text {th }}$ Intersociety Energy Conversion Engineering Conference, held in State Line, Nevada, 12-17 September 1976.

${ }^{20}$ Bennett, Gary L., Hemler, Richard J., and Schock, Alfred, "Development and Use of the Galileo and Ulysses Power Sources", Space Technology, Vol. 15, No. 3, pp. 157-174 (1995). Originally presented as Paper IAF-94-R-1-362 at the 45 ${ }^{\text {th }}$ Congress of the International Astronautical Federation, Jerusalem, Israel, 9-14 October 1994.

${ }^{21}$ Lockheed Martin, GPHS-RTGs In Support of the Cassini RTG Program, Final Technical Report, 11 January 1991 through 30 April 1998, Document No. RR18, Lockheed Martin Astronautics, Valley Forge Operations, August 1998

${ }^{22}$ Ottman, Geffrey K. and Hersman, Christopher B., "The Pluto-New Horizons RTG and Power System Early Mission Performance", AIAA-2006-4029, $4^{\text {th }}$ International Energy Conversion Engineering Conference, held in San Diego, California, 26-29 June 2006.

${ }^{23}$ Cockfield, Robert D., "Preparation of RTG F8 for the Pluto New Horizons Mission", AIAA-2006-4031, $4^{\text {th }}$ International Energy Conversion Engineering Conference, held in San Diego, California, 26-29 June 2006. 
${ }^{24}$ Ponomarev-Stepnoi, Nikolai N., Talyzin, Victor M., and Usov, Veniamin A., "Russian space nuclear power and nuclear thermal propulsion systems", Nuclear News, Vol. 43, No. 13, pp. 33-46, December 2000.

${ }^{25}$ Bennett, Gary L., "A Look at the Soviet Space Nuclear Power Program”, Paper Number 899009, in Proceedings of the $24^{\text {th }}$ Intersociety Energy Conversion Engineering Conference, held in Crystal City, Virginia, 7-11 August 1989.

${ }^{26}$ Bennett, Gary L., “The Safety Review and Approval Process for Space Nuclear Power Sources”, Nuclear Safety, Vol. 32 , No. 1, pp. 1-18 (January-March 1991).

${ }^{27}$ Bennett, Gary L., "Soviet Space Nuclear Reactor Incidents: Perception Versus Reality”, in Space Nuclear Power Systems 1989, edited by M. S. El-Genk and M. D. Hoover, Orbit Book Company, Malabar, Florida, 1992. 